Published in final edited form as:

Clin Geriatr Med. 2015 February ; 31(1): 101-ix. doi:10.1016/j.cger.2014.08.021.

\title{
Diabetes and Cognition
}

\author{
Elizabeth Rose Mayeda, PhD, MPH [Postdoctoral Fellow], \\ Department of Epidemiology and Biostatistics, University of California, San Francisco, 185 Berry \\ Street, Lobby 5, Suite 5700, San Francisco, CA 94107, Phone: 415-514-8018
}

Rachel A. Whitmer, PhD [Senior Research Scientist], and Epidemiology, Etiology \& Prevention, Kaiser Permanente Division of Research, 2000 Broadway, Oakland, CA 94612, Phone: 510-891-3400

\section{Kristine Yaffe, MD [Vice Chair for Research, Scola Endowed Professor] Departments of Psychiatry, Neurology, and Epidemiology and Biostatistics, University of California, San Francisco, San Francisco VA Medical Center, Box VAMC - 181, San Francisco, CA. 94143, Phone: 415-221-4810}

Elizabeth Rose Mayeda: Elizabeth.Mayeda@ucsf.edu; Rachel A. Whitmer: Rachel.Whitmer@kp.org; Kristine Yaffe: Kristine.Yaffe@ucsf.edu

\section{Synopsis}

Dementia is a major cause of disability among older adults and is the fifth leading cause of death among older adults in the U.S. Evidence from epidemiologic studies suggest older adults with type 2 diabetes (T2D) are 50-100\% more likely to develop dementia than those without T2D. However, studies examining the effect of T2D on cognitive decline have been less definitive, and it remains to be determined whether this association reflects a causal relationship between $\mathrm{T} 2 \mathrm{D}$ and dementia pathogenesis. There are multiple proposed mechanisms through which T2D could cause cognitive decline and dementia, including the effects of insulin dysregulation and chronic hyperglycemia on both Alzheimer's disease and vascular pathology in the brain. Neuropathological and neuroimaging studies suggest that cerebral infarcts and brain atrophy are more common in older adults with T2D. Health care providers should be aware that older adults with T2D have an increased risk for development of dementia and should be attentive in looking for cognitive problems in older patients with T2D. More research is needed to elucidate the link between T2D and dementia and to identify strategies to maintain cognitive function among people with T2D.

\section{Keywords}

Type 2 diabetes; Cognition; Cognitive decline; Dementia; Aging; Epidemiology

\footnotetext{
(c) 2014 Elsevier Inc. All rights reserved.

Correspondence to: Elizabeth Rose Mayeda, Elizabeth. Mayeda@ucsf.edu.
}

Publisher's Disclaimer: This is a PDF file of an unedited manuscript that has been accepted for publication. As a service to our customers we are providing this early version of the manuscript. The manuscript will undergo copyediting, typesetting, and review of the resulting proof before it is published in its final citable form. Please note that during the production process errors may be discovered which could affect the content, and all legal disclaimers that apply to the journal pertain. 


\section{Introduction}

Type 2 diabetes (T2D) is highly prevalent among older adults, with more than a quarter of adults $\searrow 65$ in the U.S. affected by T2D. ${ }^{1}$ As the population ages, ${ }^{2}$ the prevalence of T2D increases, ${ }^{3}$ and the life expectancy for people with T2D extends, ${ }^{4}$ understanding the epidemiology of geriatric outcomes, including cognitive decline and dementia, among older adults with T2D is very important. Dementia is a major cause of disability among older adults and is the fifth leading cause of death for older adults in the U.S. ${ }^{5}$ While current pharmacological treatments for dementia can moderately improve dementia symptoms, no currently available treatment can reverse the neuronal damage or affect disease progression. ${ }^{6}$ Understanding the relationship between T2D and dementia could help identify possible strategies for prevention and treatment of dementia.

The goal of this review is to summarize the existing evidence evaluating the relationship between T2D and dementia. We will begin with an overview of dementia and a description of potential mechanisms linking T2D and dementia. Next, we will review evidence from longitudinal epidemiologic studies examining the relationship between T2D and incidence of dementia and cognitive decline, and we will also review evidence from autopsy and brain imaging studies. Finally, we will discuss risk factors for dementia among older adults with T2D.

\section{Disease description}

\section{Overview of dementia}

Dementia is a syndrome defined as a decline in at least two cognitive domains that is severe enough to interfere with daily activities. ${ }^{7,8}$ Alzheimer's disease and vascular dementia are the two most common causes of dementia, and it is increasingly recognized that most older adults with dementia have both Alzheimer's disease and vascular pathologies. ${ }^{9-12}$ In addition to studying dementia, examining rate of cognitive decline is important for understanding the effects of T2D on cognition among older adults.

Mild cognitive impairment (MCI) is a syndrome of modest cognitive decline that does not interfere with ability to perform activities of daily life that is considered to be a symptomatic pre-dementia state. ${ }^{13}$ Not everyone with MCI will progress to dementia, but individuals with MCI develop dementia at higher rates and have higher mortality rates than people with normal cognition. ${ }^{13,14}$

\section{Alzheimer's disease and vascular dementia}

Alzheimer's disease and vascular dementia are thought to be the two most common causes of dementia. ${ }^{6,15}$ Alzheimer's disease is characterized pathologically by neuritic plaques (extracellular deposits of beta-amyloid peptides), neurofibrillary tangles (intraneural fibrils of primarily hyperphysphorlylated tau protein), loss of synapses and neurons, and brain atrophy. ${ }^{16}$ Beta-amyloid dysregulation, which leads to plaque formation, is thought to precede synaptic dysfunction and neuronal loss in Alzheimer's disease. ${ }^{9,16}$ Vascular dementia (also called vascular cognitive impairment) is characterized by macrovascular and 
microvascular cerebrovascular disease, including clinical stroke and subclinical vascular brain injury. ${ }^{9}$

Diagnosis of Alzheimer's disease and vascular dementia in clinical practice are based on objective cognitive assessments, such as neuropsychological testing and history-taking from the individual or an informant. ${ }^{8}$ Brain autopsy studies have shown that most older people with dementia have both Alzheimer's disease and cerebrovascular pathology $9-12$ and that Alzheimer's disease pathology and infarcts are commonly present in the brains of cognitively normal older adults. ${ }^{10,11,17}$ These findings suggest that Alzheimer's disease pathology, cerebrovascular pathology, and cognitive reserve ${ }^{18}$ interact in the development of dementia. ${ }^{9}$ Since most people with dementia likely have mixed pathologies, this review will focus on studies of "all-cause" dementia, rather than clinically diagnosed Alzheimer's disease or vascular dementia.

\section{Potential mechanisms}

The interaction between Alzheimer's disease pathology, cerebrovascular pathology, and cognitive reserve ${ }^{18}$ in development of dementia ${ }^{9}$ and the complexity of metabolic dysregulation in T2D makes it difficult to identify the mechanisms linking T2D and dementia. The proposed mechanisms include the effects of hyperglycemia and insulin dysregulation (hyperinsulinemia and insulin resistance) on Alzheimer's disease pathology and macrovascular and microvascular pathology in the brain. Figure 1 illustrates the potential mechanisms linking T2D and dementia. It is beyond the scope of this article to cover all possible mechanisms, but this article will discuss commonly discussed mechanisms.

\section{Pathophysiology of type 2 diabetes}

T2D is a complex and heterogeneous metabolic disorder that typically begins with insulin resistance, which is linked with physical inactivity and obesity. ${ }^{19}$ In insulin resistance, cells do not use insulin properly, and tissues need more insulin to help glucose enter cells, leading to hyperinsulinemia. Over time, the pancreas loses the ability to secrete enough insulin, and plasma glucose levels rise. It is well-established that long-term complications of T2D include microvascular and macrovascular disease throughout the body, including ischemic stroke in the brain. ${ }^{20}$ The complexity and heterogeneity of the metabolic dysregulation in T2D and the many years over which it develops and could theoretically have neurologic effects presents a challenge in identifying the neurologic effects of T2D.

\section{Chronic hyperglycemia}

Glucose is the primary source of energy for the brain, but chronic hyperglycemia is known to cause damage to the macrovasculature and microvasculature throughout the body, including ischemic stroke, which can lead to dementia. ${ }^{15}$ Retinopathy is a well-established microvascular T2D complication for which there is strong evidence of a causal link with chronic hyperglycemia. ${ }^{20}$ Retinal and cerebral arterioles share morphological and physiological properties, so retinal microvascular damage is believed to be a marker of cerebral microvascular disease. ${ }^{21,22}$ This is supported by evidence from epidemiologic 
studies that have reported that retinopathy is associated with poorer cognitive function, ${ }^{23}$ faster cognitive decline, ${ }^{24}$ and higher incidence of dementia. ${ }^{25}$ This supports the hypothesis that chronic hyperglycemia leads to microvascular cerebral damage that can impair cognitive function.

One of the mechanism through which chronic hyperglycemia damages microvascular tissue is by increasing reactive oxygen species, resulting in oxidative stress. ${ }^{26}$ Oxidative damage has also been implicated in the accumulation of beta-amyloid and neurofibrillary tangles. ${ }^{2728}$

Advanced glycation end products (AGEs) are a mechanism through which chronic hyperglycemia contributes to the development of atherosclerosis. ${ }^{15}$ AGEs are compounds formed by reactions between proteins, lipids, or nucleic acids and reducing sugars, such as glucose that accumulate during aging, but hyperglycemic environments facilitate the creation of AGEs. ${ }^{29}$ In addition to contributing to vascular disease, AGEs are found in amyloid plaques and neurofibrillary tangles in people with Alzheimer's disease, ${ }^{30}$ suggesting that AGEs contribute to Azlheimer's disease pathogenesis. The link between AGEs and dementia is further supported by the finding that circulating AGE levels are associated with greater cognitive decline in dementia-free older adults with and without T2D. ${ }^{31}$

\section{Insulin dysregulation}

In addition to addition to cerebral glucose utilization, insulin has multiple other functions in the brain that support neuronal function, including synaptogenesis, synaptic remodeling, and modulating neurotransmitter levels. ${ }^{32}$ Insulin dysregulation includes pathways linked with hyperinsulinemia and functional insulin deficiency in the brain. Insulin dysregulation may impair beta-amyloid clearance in the brain and lead to plaque formation by regulating expression of and competing for insulin-degrading enzyme (IDE), which degrades betaamyloid in addition to insulin. ${ }^{33}$ Additional mechanisms through which insulin dysregulation may lead to Alzheimer's disease and cerebrovascular pathology include the effects of insulin resistance and hyperinsulinemia on cerebral glucose metabolism, hyperphosphorylation of tau, vascular dysfunction, lipid metabolism, oxidative stress, and inflammation. ${ }^{32}$

\section{Inflammation}

Inflammatory mechanisms have also been implicated in pathogenesis of Alzheimer's disease ${ }^{28,34}$ and vascular dementia. ${ }^{15}$ In epidemiologic studies, serum inflammatory markers have been linked with cognitive decline ${ }^{35}$ and risk of dementia ${ }^{36}$ in older adults. Inflammation has been implicated in development of T2D via contributing to insulin resistance, ${ }^{37}$ and insulin dysregulation and chronic hyperglycemia may in turn also promote inflammation. ${ }^{37}$

\section{Non-causal factors that may contribute to association between T2D and dementia}

In addition to mechanisms reflecting a causal relationship between T2D and dementia, shared determinants of T2D and dementia may confound the association. Possible confounders include socioeconomic factors, such as educational and occupational 
attainment, behavioral factors, such as diet and physical activity, and co-morbidities, such as obesity and hypertension. While many studies adjust for these factors, residual confounding may still be present. Reverse causation may also contribute to the observed association between T2D and dementia. Dementia pathology is thought to start to develop decades prior to manifestation of clinical symptoms, ${ }^{9}$ which presents a challenge to establishing temporality, even in longitudinal studies.

\section{Epidemiologic literature on T2D and risk of dementia}

\section{T2D and all-cause dementia}

Table 1 summarizes results from longitudinal epidemiologic studies examining the relationship between T2D and risk of dementia. Estimates of the relative risk of dementia among people with T2D compared to those without T2D from longitudinal studies range from 1.2-2.8, although the confidence intervals from some studies include the null. The pooled risk estimate from a recent meta-analyses of nineteen longitudinal cohort studies published through 2010 suggested that older adults with T2D have approximately a 50\% increased risk of dementia compared to those without T2D (RR: 1.51, 95\% CI: 1.31-1.74). ${ }^{38}$ More recent studies support an effect size that is at least this large, with risk estimates ranging from 1.6-2.4. ${ }^{39-42}$

Because pathogenesis of dementia is thought to begin many years prior to expression of clinical symptoms, examining the relationship between midlife T2D and late-life dementia is of great interest. Three longitudinal cohort studies have examined the relationship between midlife T2D and risk of dementia over a period of 14-35 years. ${ }^{43-45}$ The association between T2D and incidence of dementia was strong in all three studies, which reported hazard ratio estimates ranging from 1.5-2.8.

\section{T2D and Alzheimer's disease and vascular dementia}

A number of studies have attempted to examine the relationship between T2D and Alzheimer's disease and vascular dementia, rather than "all-cause" dementia. Overall, there is a stronger association with vascular dementia than Alzheimer's disease in the literature. In a recent meta-analysis of sixteen studies examining Alzheimer's disease and ten studies examining vascular dementia, the pooled relative risk for T2D on vascular dementia is larger than the effect size for T2D on Alzheimer's disease (vascular dementia RR: 2.48, 95\% CI: $2.08-2.96$ vs. Alzheimer's disease RR:1.46, 95\% CI: 1.20-1.77). ${ }^{38}$ Additionally, the association between T2D and vascular dementia was relatively consistent across studies, and there was considerable variability in the association between T2D and Alzheimer's disease.

However, the results of these results should be interpreted with caution, since most dementia cases are thought to be due to mixed Alzheimer's disease and vascular pathologies. ${ }^{9-12}$

\section{T2D and cognitive decline}

Cross sectional studies generally report modestly lower cognitive test scores among people with T2D compared to people without. A recent meta-analysis reported median effect sizes of 0.3-0.5 standard deviation units across cognitive domains. ${ }^{46}$ Evidence relating T2D and cognitive decline is less consistent. Many studies report an association between T2D and 
decline in one or more domains, but across studies, there is not a consistent association between T2D and decline in individual domains. One of the most frequently assessed domains in longitudinal studies examining T2D and cognitive change is processing speed; while multiple studies have reported an association between T2D and accelerated decline in processing speed, ${ }^{47-51}$ several studies have not found an association. ${ }^{52-54} \mathrm{~T} 2 \mathrm{D}$ and change in memory over time has also been frequently assessed, and while several studies have found an association between T2D and change in memory over time, ${ }^{49,52,55}$ some other studies have not. ${ }^{48,50,56}$ Evidence is also mixed for change in executive functioning $49,51,56$ and verbal fluency. ${ }^{48,53,55}$ The inconsistency of results across studies a weak relationship between T2D and rate of cognitive change or may be due to the cognitive domains assessed, the specific neuropsychological tests used, how rate of cognitive decline was modeled, length of the study, or differences in characteristics of study populations.

\section{Evidence from neuropathological and neuroimaging studies}

Neuropathological and neuroimaging studies can help elucidate the mechanisms linking T2D and dementia. Most neuropathological studies have found more infarcts in the brains of people with T2D, but have not found evidence of greater burden of Alzheimer's disease pathology (beta-amyloid plaques and neurofibrillary tangles), with some studies reporting less Alzheimer's disease pathology in the brains of people with T2D. ${ }^{57-61}$ However, in contrast to these findings, evidence from a recent neuropathological study reported a twofold increased risk of autopsy-confirmed Alzheimer's disease among older adults with T2D compared to those without. 40

Neuroimaging studies provide the opportunity to examine brain pathology in vivo, often in larger study samples that are less prone to selection-bias than autopsy studies. Structural MRI (magnetic resonance imaging) studies have consistently reported an association between T2D and cortical and subcortical cerebral atrophy among older adults. ${ }^{56,62-67}$ It is important to note that cerebral atrophy is not a marker of a specific pathology and can represent neuronal loss from Alzheimer's disease or cerebrovascular disease. ${ }^{68}$ Thus, while this evidence suggests an effect of T2D on neuronal loss, it does not indicate the specific disease process underlying this change. The association between T2D and cerebral infarcts in structural MRI studies is also relatively consistent across studies. ${ }^{62-65,67}$ The association between T2D and white matter hyperintensities, a marker of microvascular cerebral damage, has been inconsistent, ${ }^{62,64-67}$ but current structural MRI markers of microvascular disease in the brain may not represent the full spectrum microvascular damage to the brain that may be relevant for dementia. ${ }^{69}$ A recent small study assessed beta-amyloid levels using carbon 11labeled Pittsburgh Compound B $\left({ }^{11} \mathrm{C}-\mathrm{PiB}\right)$ on positron emission tomography (PET) and found no difference in beta-amyloid deposition by glucose tolerance (dichotomized as high vs. low) or insulin resistance (dichotomized as high vs. low). ${ }^{70}$

Taken together, current evidence from neruopathological and neuroimaging studies suggest that T2D can lead to cerebrovascular damage and brain atrophy, but there is less evidence that T2D leads to Alzheimer's disease pathology. More research is needed to better understand the pathological effects of T2D on the brain. 


\section{Risk factors for dementia among people with T2D}

Glycemic control is a central aspect of T2D care and is typically measured by glycosylate $\mathrm{d}$ hemoglobin (A1c) levels, a measure of the amount of glucose that binds to hemoglobin in red blood cells and represents average glycemic control over several months. ${ }^{20}$ Among older adults with T2D, higher A1c levels are associated with lower cognitive function ${ }^{47,55}$ and accelerated cognitive decline. ${ }^{55}$ Longer duration of T2D and higher A1c levels have been shown to be associated with faster cognitive decline in middle-aged adults with T2D. ${ }^{49,55}$ Higher average glucose levels have been shown to be associated with incidence of dementia, not only among older adults with T2D, but also among those without T2D. ${ }^{71}$

Severe hypoglycemic events may also contribute to development of dementia in older adults with T2D. Moderate hypoglycemia impairs cognitive function, ${ }^{72}$ and severe hypoglycemia may cause neuronal damage. ${ }^{72,73}$ Some epidemiologic studies support this hypothesis, as severe hypoglycemic episodes have also been associated with lower cognitive function, faster cognitive decline, and an increased risk of dementia among older adults with T2D. ${ }^{74-76}$ However, the relationship between hypoglycemia and dementia may be bidirectional, with hypoglycemic events increasing risk of dementia and impaired cognitive function increasing the risk of hypoglycemic events. ${ }^{75,76}$

Depression and depressive symptoms have been linked with an increased risk of dementia in the general population. ${ }^{77}$ Depression is more common among people with T2D than in the general population; it is estimated that nearly $20 \%$ of adults with T2D have depression. ${ }^{78}$ [In this issue Park et. al., "Depression among older adults with diabetes mellitus," provides a detailed discussion.] Two recent studies of members of two separate integrated health care delivery systems found that T2D patients with comorbid depression were twice as likely to develop dementia over five years compared to T2D patients without depression. ${ }^{79,80}$ In the Action to Control Cardiovascular Risk in Diabetes-Memory in Diabetes (ACCORD-MIND) study, participants with depression experienced greater decline in psychomotor speed, verbal memory, and executive function (all domains assessed in this study) over 40 months. ${ }^{81}$ Since depression is potentially modifiable, future research is needed to identify whether interventions to treat depression can also reduce cognitive decline in people with T2D.

A 10-year dementia risk score has been developed and validated specifically for older adults with T2D based on two large longitudinal cohort studies. ${ }^{82}$ This risk score is based on predictors assessable in a primary-care setting and encompasses T2D-specific characteristics. Out of 45 candidate predictors identified from the literature, age, education, microvascular disease, lower extremity complications, cerebrovascular disease, cardiovascular disease, acute metabolic events, and depression were most strongly predictive of dementia. Interestingly, the predictive value of end-organ complications that indicate prolonged exposure to hyperglycemia and cardiovascular risk factors was higher than the predictive value of duration of T2D and A1c levels.

Among people with T2D, some racial/ethnic groups may have a higher risk of dementia. Among older T2D patients, dementia incidence was 40-60\% higher among African Americans and Native Americans compared to Asian Americans, and dementia incidence 
was intermediate among non-Hispanic whites and Latinos, even after controlling for sociodemographic factors and clinical characteristics. ${ }^{83}$

\section{References}

1. Centers for Disease Control and Prevention. National diabetes fact sheet: national estimates and general information on diabetes and prediabetes in the United States, 2011. 2011. http:// www.cdc.gov/diabetes/pubs/pdf/ndfs_2011.pdf

2. Werner, CA. The Older Population: 2010. Washington, D.C.: U.S. Census Bureau; 2011.

3. Diabetes Data \& Trends 2013. Centers for Disease Control and Prevention; 2014. Crude and AgeAdjusted Percentage of Civilian, Noninstitutionalized Adults with Diagnosed Diabetes, United States, 1980-2011. http://www.cdc.gov/diabetes/statistics/prev/national/figageadult.htm [Accessed 01/13/2014]

4. Gregg EW, Cheng YJ, Saydah S, et al. Trends in death rates among u.s. Adults with and without diabetes between 1997 and 2006: findings from the national health interview survey. Diabetes Care. Jun; 2012 35(6):1252-1257. [PubMed: 22619288]

5. Heron, M. Deaths: Leading Causes for 2013. National Center for Health Statistics; 2013.

6. Thies W, Bleiler L, Alzheimer's A. 2013 Alzheimer's disease facts and figures. Alzheimer's \& dementia : the journal of the Alzheimer's Association. Mar; 2013 9(2):208-245.

7. American Psychiatric Association. Diagnostic and statistical manual of mental disorders. 4th. Washington, DC: American Psychiatric Publishing; 2000. text rev

8. McKhann GM, Knopman DS, Chertkow H, et al. The diagnosis of dementia due to Alzheimer's disease: Recommendations from the National Institute on Aging-Alzheimer's Association workgroups on diagnostic guidelines for Alzheimer's disease. Alzheimer's \& Dementia. 2011; 7(3): 263-269.

9. Jack CR Jr, Knopman DS, Jagust WJ, et al. Tracking pathophysiological processes in Alzheimer's disease: an updated hypothetical model of dynamic biomarkers. Lancet neurology. Feb; 2013 12(2): 207-216.

10. Schneider JA, Arvanitakis Z, Bang W, Bennett DA. Mixed brain pathologies account for most dementia cases in community-dwelling older persons. Neurology. Dec 11; 2007 69(24):21972204. [PubMed: 17568013]

11. Brayne C, Richardson K, Matthews FE, et al. Neuropathological correlates of dementia in over-80year-old brain donors from the population-based Cambridge city over-75s cohort (CC75C) study. Journal of Alzheimer's disease : JAD. 2009; 18(3):645-658.

12. Echavarri C, Burgmans S, Caballero MC, Garcia-Bragado F, Verhey FR, Uylings HB. Cooccurrence of different pathologies in dementia: implications for dementia diagnosis. Journal of Alzheimer's disease : JAD. 2012; 30(4):909-917.

13. Roberts R, Knopman DS. Classification and epidemiology of MCI. Clinics in geriatric medicine. Nov; 2013 29(4):753-772. [PubMed: 24094295]

14. Campbell NL, Unverzagt F, LaMantia MA, Khan BA, Boustani MA. Risk factors for the progression of mild cognitive impairment to dementia. Clinics in geriatric medicine. Nov; 2013 29(4):873-893. [PubMed: 24094301]

15. Gorelick PB, Scuteri A, Black SE, et al. Vascular Contributions to Cognitive Impairment and Dementia A Statement for Healthcare Professionals From the American Heart Association/ American Stroke Association. Stroke. 2011; 42(9):2672-2713. [PubMed: 21778438]

16. Weiner MW, Aisen PS, Jack CR Jr, et al. The Alzheimer's disease neuroimaging initiative: progress report and future plans. Alzheimer's \& dementia : the journal of the Alzheimer's Association. May; 2010 6(3):202-211 e207.

17. Bennett DA, Schneider JA, Arvanitakis Z, et al. Neuropathology of older persons without cognitive impairment from two community-based studies. Neurology. Jun 27; 2006 66(12):18371844. [PubMed: 16801647]

18. Tucker AM, Stern Y. Cognitive reserve in aging. Current Alzheimer research. Jun; 2011 8(4):354360. [PubMed: 21222591] 
19. Stumvoll M, Goldstein BJ, van Haeften TW. Type 2 diabetes: principles of pathogenesis and therapy. Lancet. Apr 9-15; 2005 365(9467):1333-1346. [PubMed: 15823385]

20. American Diabetes A. Standards of medical care in diabetes--2014. Diabetes Care. Jan; 2014 37(Suppl 1):S14-80. [PubMed: 24357209]

21. Patton N, Aslam T, Macgillivray T, Pattie A, Deary IJ, Dhillon B. Retinal vascular image analysis as a potential screening tool for cerebrovascular disease: a rationale based on homology between cerebral and retinal microvasculatures. Journal of anatomy. Apr; 2005 206(4):319-348. [PubMed: 15817102]

22. Liew G, Wang JJ, Mitchell P, Wong TY. Retinal vascular imaging: a new tool in microvascular disease research. Circulation Cardiovascular imaging. Sep; 2008 1(2):156-161. [PubMed: 19808533]

23. Haan M, Espeland MA, Klein BE, et al. Cognitive function and retinal and ischemic brain changes: the Women's Health Initiative. Neurology. Mar 27; 2012 78(13):942-949. [PubMed: 22422889]

24. Lesage SR, Mosley TH, Wong TY, et al. Retinal microvascular abnormalities and cognitive decline: the ARIC 14-year follow-up study. Neurology. Sep 15; 2009 73(11):862-868. [PubMed: 19752453]

25. Exalto LG, Biessels GJ, Karter AJ, Huang ES, Quesenberry CP, Whitmer RA. Severe Diabetic Retinal Microvascular Eye Disease and Dementia Risk in Type 2 Diabetes. Journal of Alzheimer's Disease. 2014 In press.

26. Ceriello A, Taboga C, Tonutti L, et al. Evidence for an independent and cumulative effect of postprandial hypertriglyceridemia and hyperglycemia on endothelial dysfunction and oxidative stress generation: effects of short- and long-term simvastatin treatment. Circulation. Sep 3; 2002 106(10):1211-1218. [PubMed: 12208795]

27. Nunomura A, Perry G, Aliev G, et al. Oxidative damage is the earliest event in Alzheimer disease. Journal of neuropathology and experimental neurology. Aug; 2001 60(8):759-767. [PubMed: 11487050]

28. Galasko D, Montine TJ. Biomarkers of oxidative damage and inflammation in Alzheimer's disease. Biomarkers in medicine. Feb; 2010 4(1):27-36. [PubMed: 20383271]

29. Goldin A, Beckman JA, Schmidt AM, Creager MA. Advanced glycation end products sparking the development of diabetic vascular injury. Circulation. 2006; 114(6):597-605. [PubMed: 16894049]

30. Srikanth V, Maczurek A, Phan T, et al. Advanced glycation endproducts and their receptor RAGE in Alzheimer's disease. Neurobiology of aging. 2011; 32(5):763-777. [PubMed: 19464758]

31. Yaffe K, Lindquist K, Schwartz AV, et al. Advanced glycation end product level, diabetes, and accelerated cognitive aging. Neurology. Oct 4; 2011 77(14):1351-1356. [PubMed: 21900628]

32. Craft S, Cholerton B, Baker LD. Insulin and Alzheimer's disease: untangling the web. Journal of Alzheimer's disease : JAD. 2013; 33(Suppl 1):S263-275.

33. Craft, S. The Role of Insulin Dysregulation in Aging and Alzheimer's Disease. In: Craft, S.; Christen, Y., editors. Diabetes, Insulin and Alzheimer's Disease. Springer-Verlag; Berlin Heidelberg: 2010.

34. Akiyama H, Barger S, Barnum S, et al. Inflammation and Alzheimer's disease. Neurobiol Aging. May-Jun;2000 21(3):383-421. [PubMed: 10858586]

35. Yaffe K, Lindquist K, Penninx BW, et al. Inflammatory markers and cognition in well-functioning African-American and white elders. Neurology. Jul 8; 2003 61(1):76-80. [PubMed: 12847160]

36. Schmidt R, Schmidt H, Curb JD, Masaki K, White LR, Launer LJ. Early inflammation and dementia: a 25-year follow-up of the Honolulu-Asia Aging Study. Annals of neurology. Aug; 2002 52(2):168-174. [PubMed: 12210786]

37. Dandona P, Aljada A, Bandyopadhyay A. Inflammation: the link between insulin resistance, obesity and diabetes. Trends in immunology. Jan; 2004 25(1):4-7. [PubMed: 14698276]

38. Cheng G, Huang C, Deng H, Wang H. Diabetes as a risk factor for dementia and mild cognitive impairment: a meta-analysis of longitudinal studies. Internal medicine journal. May; 2012 42(5): 484-491. [PubMed: 22372522]

39. Cheng D, Noble J, Tang MX, Schupf N, Mayeux R, Luchsinger JA. Type 2 Diabetes and LateOnset Alzheimer's Disease. Dement Geriatr Cogn Disord. Jul 15; 2011 31(6):424-430. [PubMed: 21757907] 
40. Ohara T, Doi Y, Ninomiya T, et al. Glucose tolerance status and risk of dementia in the community: the Hisayama study. Neurology. Sep 20; 2011 77(12):1126-1134. [PubMed: 21931106]

41. Kimm H, Lee PH, Shin YJ, et al. Mid-life and late-life vascular risk factors and dementia in Korean men and women. Archives of gerontology and geriatrics. May-Jun;2011 52(3):e117-122. [PubMed: 20932588]

42. Mayeda ER, Haan MN, Kanaya AK, Yaffe K, Neuhaus J. Type 2 diabetes and 10 year risk of dementia and cognitive impairment among older Mexican Americans. Diabetes Care. 2013 In Press.

43. Schnaider Beeri M, Goldbourt U, Silverman JM, et al. Diabetes mellitus in midlife and the risk of dementia three decades later. Neurology. Nov 23; 2004 63(10):1902-1907. [PubMed: 15557509]

44. Whitmer RA, Sidney S, Selby J, Johnston SC, Yaffe K. Midlife cardiovascular risk factors and risk of dementia in late life. Neurology. Jan 25; 2005 64(2):277-281. [PubMed: 15668425]

45. Alonso A, Mosley TH Jr, Gottesman RF, Catellier D, Sharrett AR, Coresh J. Risk of dementia hospitalisation associated with cardiovascular risk factors in midlife and older age: the Atherosclerosis Risk in Communities (ARIC) study. J Neurol Neurosurg Psychiatry. Nov; 2009 80(11):1194-1201. [PubMed: 19692426]

46. van den Berg E, Kloppenborg RP, Kessels RP, Kappelle LJ, Biessels GJ. Type 2 diabetes mellitus, hypertension, dyslipidemia and obesity: A systematic comparison of their impact on cognition. Biochimica et biophysica acta. May; 2009 1792(5):470-481. [PubMed: 18848880]

47. Yaffe K, Falvey C, Hamilton N, et al. Diabetes, glucose control, and 9-year cognitive decline among older adults without dementia. Arch Neurol. Sep; 2012 69(9):1170-1175. [PubMed: 22710333]

48. Knopman DS, Mosley TH, Catellier DJ, Coker LH. Fourteen-year longitudinal study of vascular risk factors, $A P O E$ genotype, and cognition: The ARIC MRI Study. Alzheimer's \& Dementia. 2009; 5(3):207-214.

49. Spauwen PJ, Köhler S, Verhey FR, Stehouwer CD, van Boxtel MP. Effects of Type 2 Diabetes on 12-Year Cognitive Change Results from the Maastricht Aging Study. Diabetes care. 2013; 36(6): 1554-1561. [PubMed: 23275366]

50. Arvanitakis Z, Wilson RS, Bienias JL, Evans DA, Bennett DA. Diabetes mellitus and risk of Alzheimer disease and decline in cognitive function. Arch Neurol. May; 2004 61(5):661-666. [PubMed: 15148141]

51. Gregg EW, Yaffe K, Cauley JA, et al. Is diabetes associated with cognitive impairment and cognitive decline among older women? Study of Osteoporotic Fractures Research Group. Archives of internal medicine. Jan 24; 2000 160(2):174-180. [PubMed: 10647755]

52. Comijs HC, Kriegsman DM, Dik MG, Deeg DJ, Jonker C, Stalman WA. Somatic chronic diseases and 6-year change in cognitive functioning among older persons. Archives of gerontology and geriatrics. Mar-Apr;2009 48(2):191-196. [PubMed: 18299158]

53. Van den Berg E, De Craen A, Biessels G, Gussekloo J, Westendorp R. The impact of diabetes mellitus on cognitive decline in the oldest of the old: a prospective population-based study. Diabetologia. 2006; 49(9):2015-2023. [PubMed: 16804671]

54. Nooyens AC, Baan CA, Spijkerman AM, Verschuren WM. Type 2 diabetes and cognitive decline in middle-aged men and women: the Doetinchem Cohort Study. Diabetes Care. Sep; 2010 33(9): 1964-1969. [PubMed: 20519662]

55. Tuligenga RH, Dugravot A, Tabák AG, et al. Midlife type 2 diabetes and poor glycaemic control as risk factors for cognitive decline in early old age: a post-hoc analysis of the Whitehall II cohort study. The Lancet Diabetes \& Endocrinology. 2013

56. Debette S, Seshadri S, Beiser A, et al. Midlife vascular risk factor exposure accelerates structural brain aging and cognitive decline. Neurology. Aug 2; 2011 77(5):461-468. [PubMed: 21810696]

57. Heitner J, Dickson D. Diabetics do not have increased Alzheimer-type pathology compared with age-matched control subjects. A retrospective postmortem immunocytochemical and histofluorescent study. Neurology. Nov; 1997 49(5):1306-1311. [PubMed: 9371913]

58. Janson J, Laedtke T, Parisi JE, O'Brien P, Petersen RC, Butler PC. Increased risk of type 2 diabetes in Alzheimer disease. Diabetes. Feb; 2004 53(2):474-481. [PubMed: 14747300] 
59. Alafuzoff I, Aho L, Helisalmi S, Mannermaa A, Soininen H. Beta-amyloid deposition in brains of subjects with diabetes. Neuropathology and applied neurobiology. Feb; 2009 35(1):60-68. [PubMed: 18346114]

60. Ahtiluoto S, Polvikoski T, Peltonen M, et al. Diabetes, Alzheimer disease, and vascular dementia: a population-based neuropathologic study. Neurology. Sep 28; 2010 75(13):1195-1202. [PubMed: 20739645]

61. Beeri MS, Silverman JM, Davis KL, et al. Type 2 diabetes is negatively associated with Alzheimer's disease neuropathology. The journals of gerontology Series A, Biological sciences and medical sciences. Apr; 2005 60(4):471-475.

62. Manschot SM, Brands AM, van der Grond J, et al. Brain magnetic resonance imaging correlates of impaired cognition in patients with type 2 diabetes. Diabetes. Apr; 2006 55(4):1106-1113. [PubMed: 16567535]

63. Espeland MA, Bryan RN, Goveas JS, et al. Influence of type 2 diabetes on brain volumes and changes in brain volumes: results from the Women's Health Initiative Magnetic Resonance Imaging studies. Diabetes Care. Jan; 2013 36(1):90-97. [PubMed: 22933440]

64. Moran C, Phan TG, Chen J, et al. Brain atrophy in type 2 diabetes: regional distribution and influence on cognition. Diabetes Care. Dec; 2013 36(12):4036-4042. [PubMed: 23939539]

65. van Harten B, de Leeuw FE, Weinstein HC, Scheltens P, Biessels GJ. Brain imaging in patients with diabetes a systematic review. Diabetes care. 2006; 29(11):2539-2548. [PubMed: 17065699]

66. Falvey CM, Rosano C, Simonsick EM, et al. Macro-and microstructural magnetic resonance imaging indices associated with diabetes among community-dwelling older adults. Diabetes care. 2013; 36(3):677-682. [PubMed: 23160721]

67. Saczynski JS, Siggurdsson S, Jonsson PV, et al. Glycemic status and brain injury in older individuals: the age gene/environment susceptibility-Reykjavik study. Diabetes Care. Sep; 2009 32(9):1608-1613. [PubMed: 19509008]

68. Jack CR Jr. Alliance for aging research AD biomarkers work group: structural MRI. Neurobiol Aging. Dec; 2011 32(Suppl 1):S48-57. [PubMed: 22078173]

69. Pantoni L. Cerebral small vessel disease: from pathogenesis and clinical characteristics to therapeutic challenges. Lancet neurology. Jul; 2010 9(7):689-701.

70. Thambisetty M, Jeffrey Metter E, Yang A, et al. Glucose intolerance, insulin resistance, and pathological features of Alzheimer disease in the Baltimore Longitudinal Study of Aging. JAMA neurology. Sep 1; 2013 70(9):1167-1172. [PubMed: 23897112]

71. Crane PK, Walker R, Hubbard RA, et al. Glucose levels and risk of dementia. New England Journal of Medicine. 2013; 369(6):540-548. [PubMed: 23924004]

72. Warren RE, Frier BM. Hypoglycaemia and cognitive function. Diabetes, obesity \& metabolism. Sep; 2005 7(5):493-503.

73. Bree AJ, Puente EC, Daphna-Iken D, Fisher SJ. Diabetes increases brain damage caused by severe hypoglycemia. American journal of physiology Endocrinology and metabolism. Jul; 2009 297(1):E194-201. [PubMed: 19435850]

74. Whitmer RA, Karter AJ, Yaffe K, Quesenberry CP Jr, Selby JV. Hypoglycemic episodes and risk of dementia in older patients with type 2 diabetes mellitus. JAMA : the journal of the American Medical Association. Apr 15; 2009 301(15):1565-1572.

75. Feinkohl I, Aung PP, Keller M, et al. Severe hypoglycemia and cognitive decline in older people with type 2 diabetes: the edinburgh type 2 diabetes study. Diabetes Care. Feb; 2014 37(2):507515. [PubMed: 24103900]

76. Yaffe K, Falvey CM, Hamilton N, et al. Association between hypoglycemia and dementia in a biracial cohort of older adults with diabetes mellitus. JAMA internal medicine. Jul 22; 2013 173(14):1300-1306. [PubMed: 23753199]

77. Byers AL, Yaffe K. Depression and risk of developing dementia. Nature reviews Neurology. Jun; 2011 7(6):323-331.

78. Ali S, Stone MA, Peters JL, Davies MJ, Khunti K. The prevalence of co-morbid depression in adults with Type 2 diabetes: a systematic review and meta-analysis. Diabetic medicine : a journal of the British Diabetic Association. Nov; 2006 23(11):1165-1173. [PubMed: 17054590] 
79. Katon W, Lyles CR, Parker MM, Karter AJ, Huang ES, Whitmer RA. Association of depression with increased risk of dementia in patients with type 2 diabetes: the Diabetes and Aging Study. Archives of general psychiatry. Apr; 2012 69(4):410-417. [PubMed: 22147809]

80. Katon WJ, Lin EH, Williams LH, et al. Comorbid depression is associated with an increased risk of dementia diagnosis in patients with diabetes: a prospective cohort study. Journal of general internal medicine. May; 2010 25(5):423-429. [PubMed: 20108126]

81. Sullivan MD, Katon WJ, Lovato LC, et al. Association of depression with accelerated cognitive decline among patients with type 2 diabetes in the ACCORD-MIND trial. JAMA psychiatry. Oct; 2013 70(10):1041-1047. [PubMed: 23945905]

82. Exalto LG, Biessels GJ, Karter AJ, et al. Risk score for prediction of 10 year dementia risk in individuals with type 2 diabetes: a cohort study. The Lancet Diabetes \& Endocrinology. 2013; 1(3):183-190. [PubMed: 24622366]

83. Mayeda ER, Karter AJ, Huang ES, Moffet HH, Haan MN, Whitmer RA. Racial/ethnic differences in dementia risk among older type 2 diabetes patients: The Diabetes and Aging Study. Diabetes Care. Nov 22.2013

84. Brayne C, Gill C, Huppert FA, et al. Vascular risks and incident dementia: results from a cohort study of the very old. Dement Geriatr Cogn Disord. May-Jun;1998 9(3):175-180. [PubMed: 9622006]

85. Ott A, Stolk RP, van Harskamp F, Pols HA, Hofman A, Breteler MM. Diabetes mellitus and the risk of dementia: The Rotterdam Study. Neurology. 1999; 53(9):1937-1942. [PubMed: 10599761]

86. Peila R, Rodriguez BL, Launer LJ, Honolulu-Asia Aging S. Type 2 diabetes, APOE gene, and the risk for dementia and related pathologies: The Honolulu-Asia Aging Study. Diabetes. Apr; 2002 51(4):1256-1262. [PubMed: 11916953]

87. MacKnight C, Rockwood K, Awalt E, McDowell I. Diabetes mellitus and the risk of dementia, Alzheimer's disease and vascular cognitive impairment in the Canadian Study of Health and Aging. Dement Geriatr Cogn Disord. 2002; 14(2):77-83. [PubMed: 12145454]

88. Hassing LB, Johansson B, Nilsson SE, et al. Diabetes mellitus is a risk factor for vascular dementia, but not for Alzheimer's disease: a population-based study of the oldest old. Int Psychogeriatr. Sep; 2002 14(3):239-248. [PubMed: 12475085]

89. Akomolafe A, Beiser A, Meigs JB, et al. Diabetes mellitus and risk of developing Alzheimer disease: results from the Framingham Study. Arch Neurol. Nov; 2006 63(11):1551-1555. [PubMed: 17101823]

90. Irie F, Fitzpatrick AL, Lopez OL, et al. Enhanced risk for Alzheimer disease in persons with type 2 diabetes and APOE epsilon4: the Cardiovascular Health Study Cognition Study. Arch Neurol. Jan; 2008 65(1):89-93. [PubMed: 18195144]

91. Xu WL, von Strauss E, Qiu CX, Winblad B, Fratiglioni L. Uncontrolled diabetes increases the risk of Alzheimer's disease: a population-based cohort study. Diabetologia. Jun; 2009 52(6):10311039. [PubMed: 19280172]

92. Raffaitin C, Gin H, Empana JP, et al. Metabolic syndrome and risk for incident Alzheimer's disease or vascular dementia: the Three-City Study. Diabetes Care. Jan; 2009 32(1):169-174. [PubMed: 18945929] 


\section{Key Points}

- Older adults with type 2 diabetes are 50-100\% more likely to develop dementia than those without diabetes.

- More research is needed to identify whether the observed association reflects a causal relationship between type 2 diabetes and dementia pathogenesis.

- The proposed link between type 2 diabetes and dementia includes mechanisms contributing to both Alzheimer's disease and vascular pathology.

- Infarcts and atrophy are more common in the brains of older adults with T2D.

- Among people with type 2 diabetes, those with longer duration of diabetes, poorer glycemic control, and more vascular complications are at the highest risk of developing dementia. 


\section{Summary}

Consistent evidence exists that older adults with T2D are more likely to develop dementia than those without T2D. The literature on the effect of T2D on cognitive decline is less consistent. From a clinical perspective, it is important to know that people with T2D have an increased risk of dementia. However, understanding whether T2D has a causal effect on cognitive decline and dementia and if so, through what mechanisms is useful for identifying potential strategies to prevent or treat dementia. The biological plausibility of the multiple pathways through which T2D could lead to development of Alzheimer's disease and vascular pathology in the brain supports the hypothesis that the link is causal, although current evidence from neuropathologic and neuroimaging studies provide more evidence to support an effect of T2D on vascular pathology than Alzheimer's disease pathology.

Health care providers should be aware that older adults with T2D have an increased risk for development of dementia. Future research is needed to elucidate the pathways linking T2D and dementia, better understand risk factors for dementia in this high-risk population, and strategies to maintain cognitive function among people with T2D. 


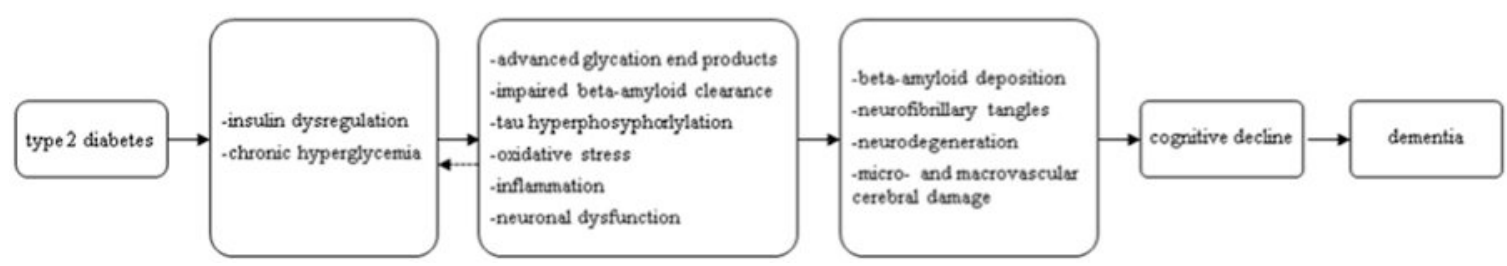

Figure 1. Figure illustrating potential causal links between type 2 diabetes and cognitive decline and dementia 


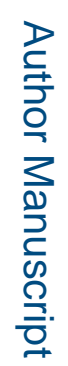

\begin{tabular}{|c|c|c|c|c|c|c|c|c|c|c|c|c|c|c|c|c|c|}
\hline 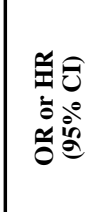 & 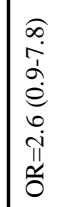 & 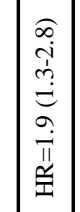 & 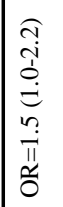 & 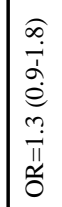 & 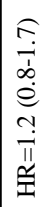 & 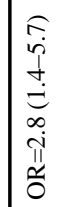 & 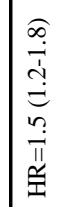 & 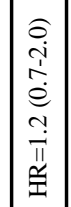 & 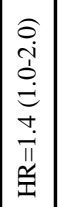 & & 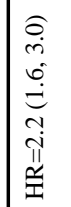 & 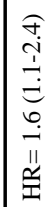 & 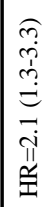 & $\begin{array}{l}\widehat{\mathcal{N}} \\
\stackrel{+}{=}\end{array}$ & 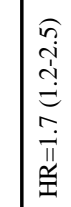 & 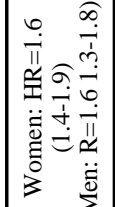 & 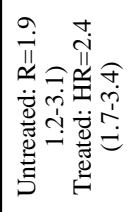 \\
\hline
\end{tabular}

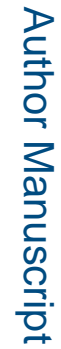

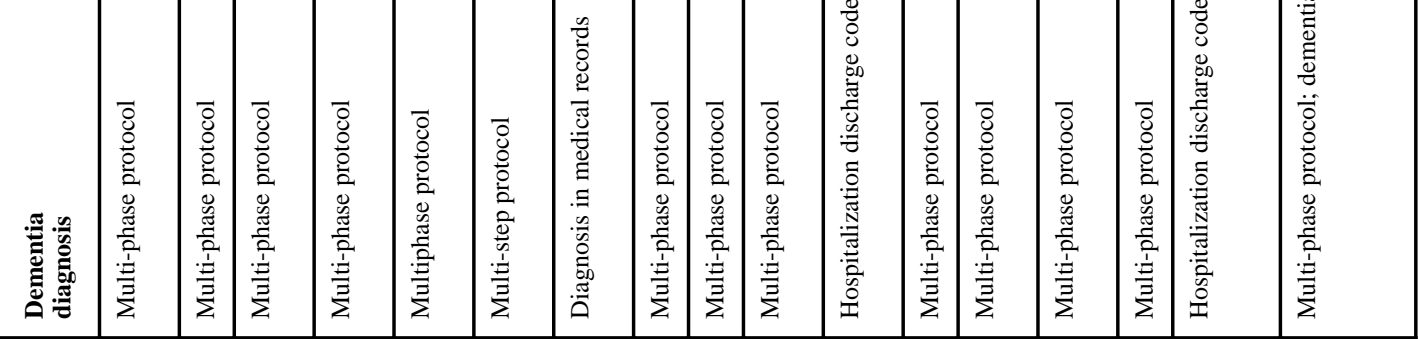

要

E

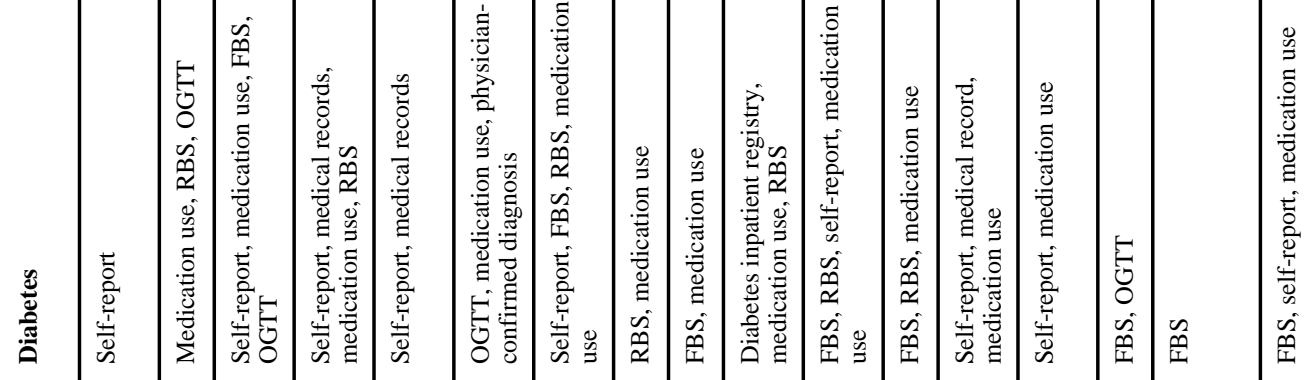

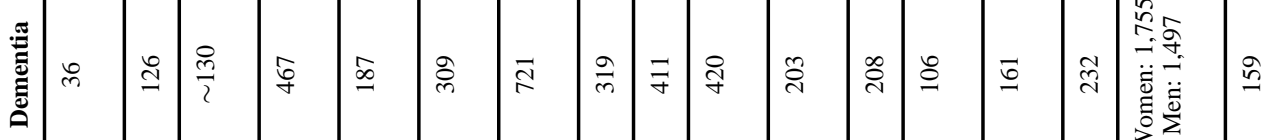

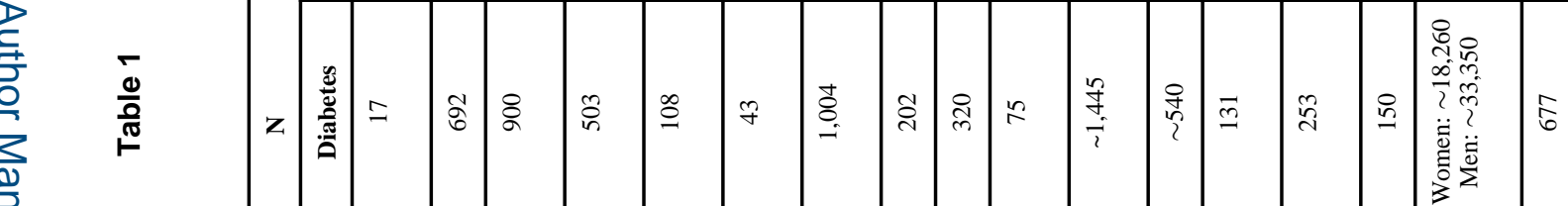

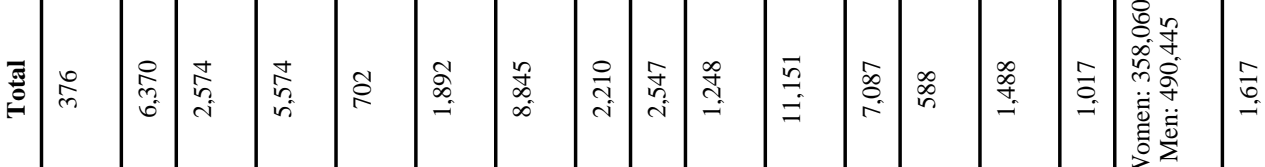

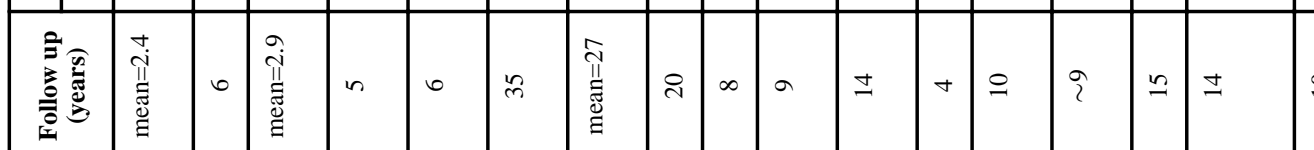

要

\begin{tabular}{|c|c|c|c|c|c|c|c|c|c|c|c|c|c|c|c|c|c|}
\hline & & & & & & & & & & & & & & & & & \\
\hline 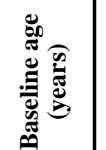 & 点 & 怘 & 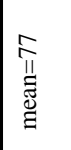 & 苦 & 志 & 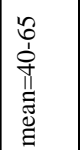 & \begin{tabular}{|l} 
寺 \\
系
\end{tabular} & 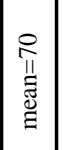 & 怘 & 志 & 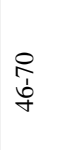 & 范 & 唯 & 克 & 志 & 然 & 吉 \\
\hline
\end{tabular}

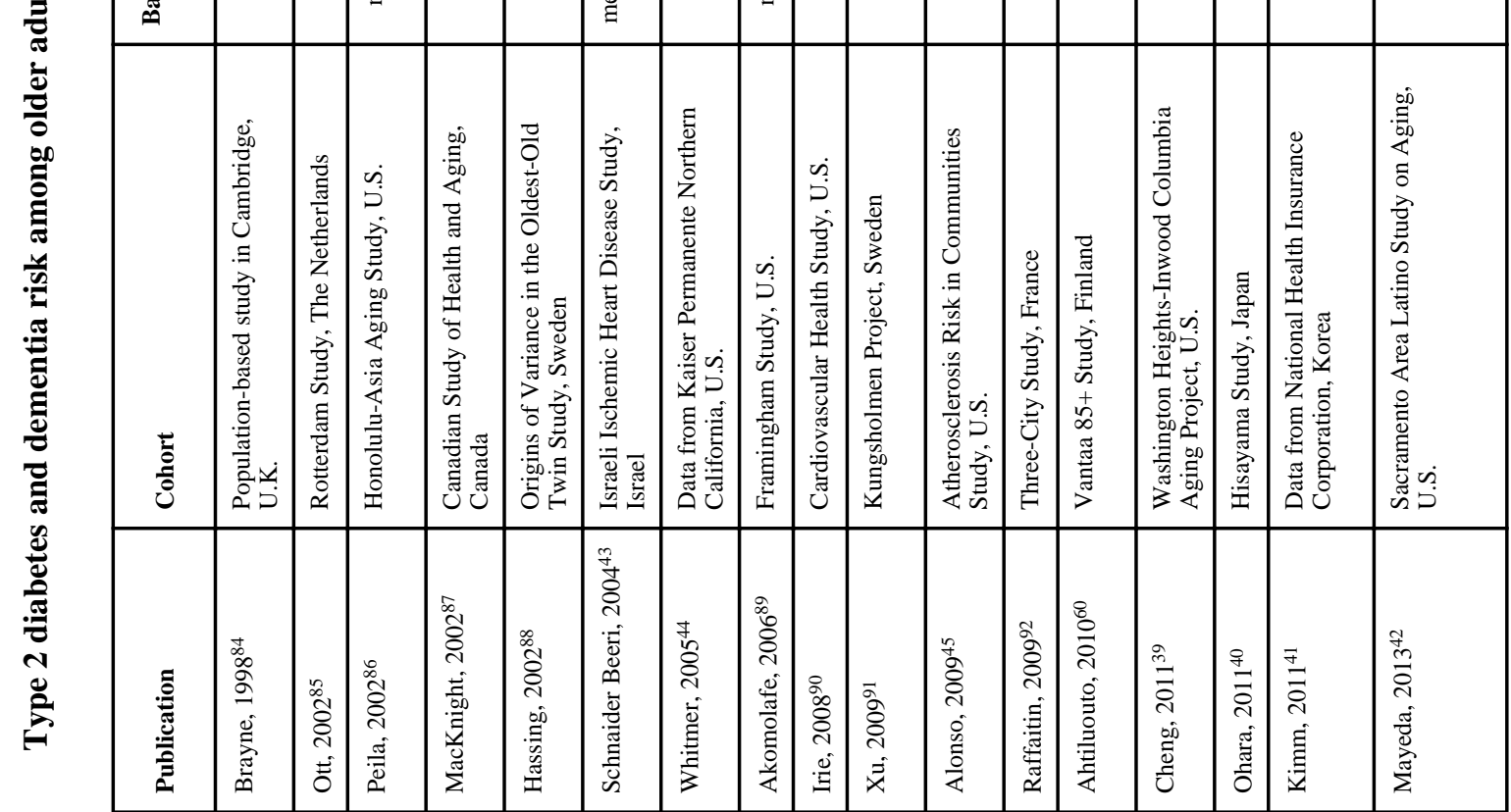


